\title{
Efficacy of Triple Pelvic Osteotomy in Canine Hip Dysplasia
}

\author{
Marius M. MUSTE ${ }^{1}$, Aurel TANASE ${ }^{2}$, Florin BETEG ${ }^{1}$, Aurel MUSTE ${ }^{1}$ \\ Radu LĂCĂTUŞ ${ }^{1}$, Teodor STROE ${ }^{1}$
}

${ }^{1}$ Faculty of Veterinary Medicine, University of Agricultural Sciences and Veterinary Medicine, Mănăştur Street 3-5, Cluj-Napoca, Romania

${ }^{2}$ Faculty of Veterinary Medicine, University of Agricultural Sciences and Veterinary Medicine, Splaiul Independenţei 105, Bucharest Romania

*Corresponding author e-mail: mustemariusmihai@yahoo.com

Bulletin UASVM Veterinary Medicine 71(2) / 2014,

Print ISSN 1843-5270; Electronic ISSN 1843-5378

DOI:10.15835/buasvmcn-vm: 10859

\begin{abstract}
Canine hip dysplasia is an affection which affects the locomotion of the animal very clear and severe. Genetical factors and others (miopathy, painful diseases associated with canine hip dysplasia, neuronal disfunction, exaggerated elasticity of the pectineu muscle) are known to be the cause of the disease.

We could also blame the feeding habits for growing puppies. During the growth period, an excess in fatty food can cause a beginning for canine hip dysplasia and other bone diseases. It is know that canine hip dysplasia affects most of the time large breed dogs. In our study we wanted to check the efficacy of the triple pelvic osteotomy (TPO) operation in unilateral canine hip dysplasia grades 3 and 4.

We took 5 dog breeds into consideration, with different gender and age, varying from 6 months to 1,3 years. The diagnostic was made observing the clinical signs and $\mathrm{X}$ ray findings. For the stabilization of the cut bone segment we used specific plates for osteosynthesis with different angles. Post operation, dogs were followed for 10 days and checked for their vital signs as well as local modifications and started using the affected limb 11 days after the operation.
\end{abstract}

Keywords: dog, hip dysplasia, triple pelvic osteotomy

\section{INTRODUCTION}

Canine hip dysplasia is a multifactorial disease which affects all large breed dogs (Everts et al., 2000). It is characterized by a congenital deformation of the hip socket (Sewell, et al., 2009) followed by an exaggerated laxity of the joint in young dogs and can develop to degenerative joint disease in the adult (B.D. Rocha et al.,2007). Clinical signs may wary from a light instability of the hind limbs to the patient refusing to move (Ohlerth et al., 1998). The diagnostic of the disease can be made by clinical examination, palpation and X-ray (Ginja MMD et al., 2010). The goal of the present study was to appreciate the efficacy of TPO in canine hip dysplasia depending on the time of intervention, age and time of healing.

\section{MATERIAL AND METHODS}

Our study was conducted during 2011-2012 on a number of 5 dogs of different breeds (Labrador, Rottweiller, Golden Retriever, Rottweiller mix) with the age between 6 months and 1,3 years. The 5 subjects were diagnosed with canine hip dysplasia grade 3 and 4 (Demko et al., 2005). We used standard orthopedic surgical equipment along with Synthes metal plates specially designed for the TPO procedure (Schultz K.S. et al., 2003). Each plate was characteristic to the grade of dysplasia (Andersen S. et al., 1988). For the surgical intervention dogs were prepped before surgery with a $12 \mathrm{~h}$ diet and 30 minutes before starting the surgery, they had a premedication with Atropine 0,15 ml s.c., Medetomidin $20 \mu \mathrm{g} /$ 
$\mathrm{kg}$ i.m and Ketamine $5 \mathrm{mg} / \mathrm{kg}$. The patients were intubated and general anesthesia was maintained with the use of Isofluran 2\% (Malm S. et al.,2 007).

The triple pelvic osteotomy procedure implies osteotomy procedures at the 3 bone segments for repositioning the pelvic socket. The patients were first positioned dorsally to have a better work space at the level of pubis. After the incision of soft tissues, the pectineus ligament was cut and pubis osteotomy was performed (Fig.1) followed by the closing of the operation. For the ischia osteotomy we performed an incision of the soft tissues located at the middle distance between the posterior ischial and lateral limit of the ischiatic arch. With the help of an osteotome we cut the caudal surface of the ischia (Fig.2) and we checked to be sure the incision was made properly.

The dog was placed on his lateral side and a 5 $\mathrm{cm}$ incision of the soft tissues was made, until the ilium was isolated. After this step, the osteotomy of the ilium was performed (Fig.3). To check

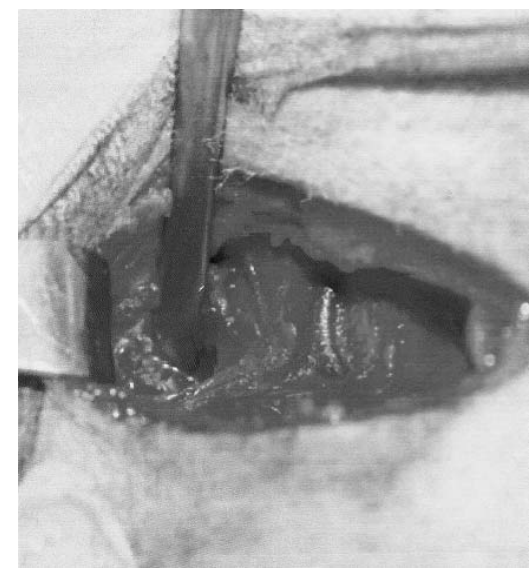

Fig.1. Pubis osteotomy

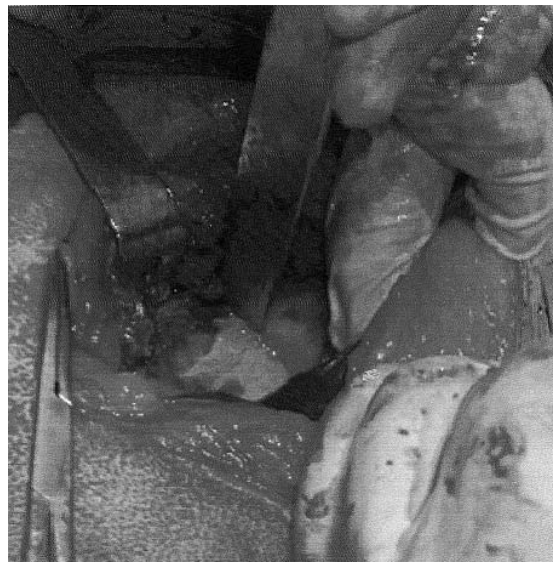

Fig.3. Ilium osteotomy the mobility of the cut bone segment, we used a Kern forceps applied at the ischia and rotation movements of the segment were made. The Synthes plate is then fixed on the segment with 6 screws (Sarierler M et al., 2012) (Fig. 4).

\section{RESULTS AND DISCUSSION}

The acetabular socket, the femur head, the capsular ligament, the round ligament and synovial membrane form a complex and very stabile joint. If one of these components are not functioning well, the socket is predisposed to a severe pathology (Hara Y. et al., 2002). The stabilization elements are widened, sometimes torn which can offer the femur head an increased movement (Lust G. 1997). From a dynamic point of view, this mobility extends past the physiological limits and produces a repeated trauma with immediate effect on the joint cartilage and synovial membrane with vascular changes, nutrition disorders of the bone and cartilage and degenerative joints (Todhunter

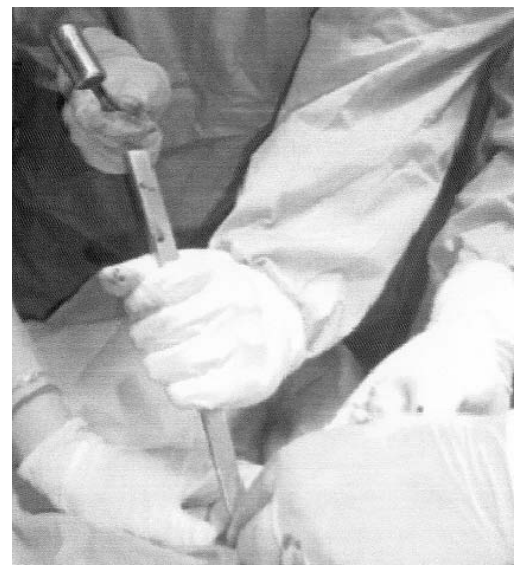

Fig.2. Ischia osteotomy

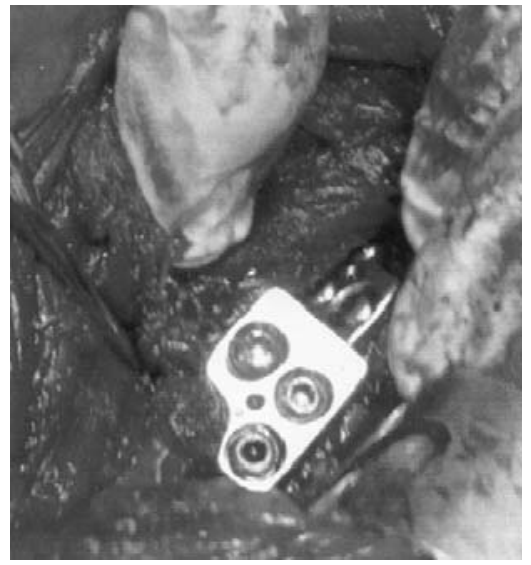

Fig.4. Attaching the plate 
RJ et al., 2003). Arthritis and arthrosis are very likely to appear and especially osteophytes which reduce even more the joint mobility. It is the reason why this disease is more and more studied. In the present, there are two solid options for canine hip dysplasia: TPO and total hip replacement (American College of Veterinary Surgeons 2008). Total hip replacement offers a more simple surgical intervention and accuracy in the correction of the joint angle because they are designed according to breed, weight, age and age of the disease. TPO requires a more elaborate work volume, the joint angle is calculated with the Norberg technique (Brass W, 1989) the surgical act is represented by a triple osteotomy and the repositioning of the femur head is not always the one desired by the surgeon. In our cases, the dogs suffered from canine hip dysplasia grade 3 and 4, this being the reason to check for the efficacy of the TPO technique. Applying the technique 5 times with 5 successful operations, we can say the method is very efficient and offers a quick healing post operation. The most critical point of the operation remains the rotation of the cut bone segment. The surgeon has to be in perfect synchronization with the other surgeon so that the Synthes plate is placed. Another signaled aspect in our study was the distance between the cut bone segments. In our study we found out that 2 or even $3 \mathrm{~mm}$ are needed so that the bone segment will be more easy to maneuver. Rotating under pressure can lead to cracks or even fractures. Because our patients were heavy, we offered an increased stability to the bone

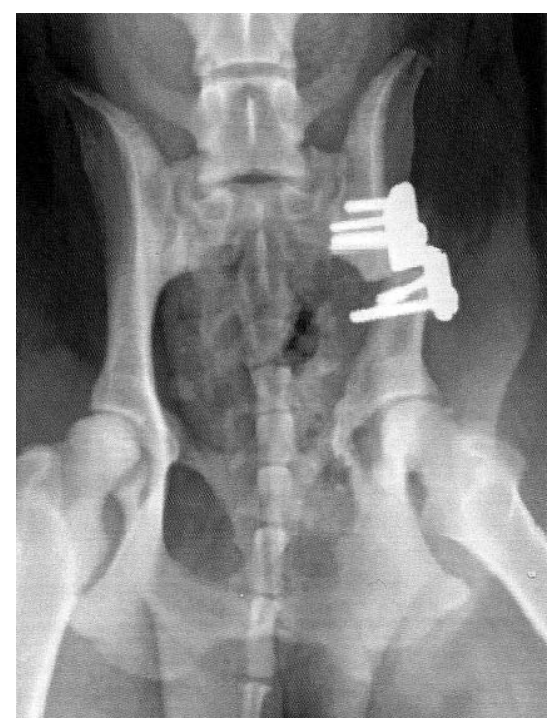

Fig.5. Post operatory X-ray segment by inserting a cerclage at the end of the ischia. At all cases, we performed a post operation $\mathrm{X}$-ray to confirm the correct insertion and fixation of the plate. Post operatory, the patients received a pain management protocol (Metamizol 1000 $\mathrm{mg}$, Amoxicilin 15mg/kg s.c.). During the recovery phase, in the first three days the patients preferred not to walk or use the other three limbs. At day 11 post operation they start to put the leg down and at day 20 they could use it completely. We did not encounter any complications in our patients.

\section{CONCLUSIONS}

TPO offers good results when treating canine hip dysplasia (7-20 days after the surgery the patient can use the operated hip). The surgical intervention has to be made as fast as possible to avoid degenerative changes in the joint. For the recovery of the patients, they need to be observed for 10 days and helped in any situation where they would need to use the affected limb.

\section{REFERENCES}

1. American College of Veterinary Surgeons 2008 Veterinary Surgery vol. 10, 65-89

2. Andersen S, Andresen E, and Christensen K (1988). Hip dysplasia selection index exemplified by data from German shepherd dogs. J Anim Breed Genet 105:112-119.

3. Brass W (1989). Hip dysplasia in dogs. Journal of Small Animal Practice. 30:166-170.

4. Demko J, McLaughlin R (2005). Developmental Orthopedic Disease. Veterinary Clinics Small Animal Practice. 35:1111-1135.

5. Everts RE, Hazewinkel HAW, Rothuizen J, van Oost BA (2000). Bone disorders in the dog: A review of modern genetic strategies to find the underlying causes. Veterinary Quarterly 22:63-70.

6. Ginja MMD, Silvestre AM, Gonzalo-Orden JM, Ferreira AJA (2010). Diagnosis, genetic control and preventive management of canine hip dysplasia: A review. The Veterinary Journal 184:269-276.

7. Hara Y, Harada Y, Fujita Y, et al. (2002). Changes of hip joint congruity after triple pelvic osteotomy in the dog with hip dysplasia. Journal of Veterinary Medical Science. 64(10):933-936.

8. Lust G (1997). An overview of the pathogenesis of canine hip dysplasia. J Am Vet Med Assoc. 210:1443-1445.

9. Malm S, Strandberg E, Danell B, Audell L, Swenson L, et al (2007). Impact of sedation method on the diagnosis of hip and elbow dysplasia in Swedish dogs. Preventive Veterinary Medicine. 78:196-209.

10. Rocha BD, Tôrres RCS (2007). Ultrasonic and radiographic study of laxity in hip joints of young dogs. Arq. Bras. Med. Vet. Zootec. 59(1):172-190. 
11. Ohlerth S, Busato A, Gaillard C, Fluckiger M, Lang J (1998). Epidemiologic and genetic studies of canine hip dysplasia in a population of Labrador retrievers: a study over 25 years. Dtsch Tierarztl Wochenschr. 105:378-383.

12. Sarierler M, Yildirim IG, Ocal MK (2012). Effect of triple pelvic osteotomy on the proximal femoral geometry in dysplastic dogs. Research in Veterinary Science. 92(1):142-146.

13. Sewell MD, RosendahlK, Eastwood DM (2009). Developmental dysplasia of the hip. British Medical Journal 339:12.
14. Schultz KS, Dejardin LM (2003). Surgical treatment of canine hip dysplasia. In Slatter D., editor; Textbook of small animal surgery, ed. 3, Philadelphia, Saunders 57120.

15. Todhunter RJ, Lust G. Hip dysplasia: pathogenesis. In: Statter D, editor. Textbook of Small Animal Surgery. $3^{\text {rd }}$ edition. Vol. 2. Philadelphia, Pa, USA: Sunders; 2003. pp. 2009-2012. 